\title{
The genetic architecture of behavioural responses to novelty in mice
}

\author{
W. E. Crusio* and \\ J. H. F. van Abeelen
}

Department of Zoology, University of Nijmegen, Toernooiveld, 6525 ED Nijmegen, The Netherlands.

The genetic architectures of 12 behavioural variables measured in adult male mice placed in a novel environment were analysed in a replicated $4 \times 4$ diallel cross. The results were combined with those obtained in a classical cross involving two of the four strains. Based on the hypothesis of an evolutionary history of stabilising selection for mouse exploratory behaviour, we expected additive genetic effects and ambidirectional dominance. Such genetic architectures were actually found for those exploratory behaviours where epistatic effects were of minor importance. Similar findings emerged for some non-exploratory phenotypes. All behaviours analysed appeared to be polygenically controlled.

\section{INTRODUCTION}

Exploratory behaviour in rodents is elicited by novel stimuli and consists of behavioural acts and postures that permit the collection of information about new objects and unfamiliar parts of the environment (Barnett, 1958; Barnett and Cowan, 1976; O'Keefe and Nadel, 1978). To measure this behaviour, many different devices have been employed such as mounted cages, photocell cages, running-wheels, open-fields, and stabilimeters. One of the most frequently used is the open-field, in which mice display a rich and varied behavioural repertoire (van Abeelen, 1963). The adaptive value of exploration seems clear: entering and exploring new places promotes dispersion and improves the chances of finding life necessities (food, shelter, and escape routes).

Because natural selection in evolutionary history must have influenced the genetic architecture of this behavioural phenotype, the latter should show traces of the past selection. Broadhurst and Jinks (1974), Mather (1973), and Roberts (1967), following Fisher (1958), have developed a line of thought which, based on the genetic underpinnings of a trait, makes inferences about past selection. Stabilising selection favours intermediate expression of the phenotype, directional selection

\footnotetext{
* Present address: Institut für Anthropologie und Humangenetik, Universität Heidelberg, Im Neuenheimer Feld 328, 6900 Heidelberg 1, Federal Republic of Germany.
}

favours either high or low expression, and disruptive selection favours more than one expression, usually both the high and low extremes. The genetic effects of these kinds of selection differ widely. We focus on the former two. Diagnostic features of stabilising selection are linkage of increasers with decreasers and either the absence of dominance or the presence of ambidirectional dominance. The broad heritability tends to be equal to the narrow. Any epistatic interactions will be small, ambidirectional, and therefore selfcancelling. Diagnostic features of a trait with a history of directional selection are a large directional dominance and low levels of additive variation. The narrow heritability is low as compared to the broad.

We hypothesise an evolutionary history of stabilising selection for mouse exploratory behaviour since, if a mouse enters a completely novel environment, it will be important to collect much information in a short time but very high exploration levels will render the animal more vulnerable to predation. In order to have an opportunity to make inferences about the evolutionary past and the adaptive value of the phenotypes concerned, we assayed their genetic architectures by employing a $4 \times 4$ diallel cross, replicated five times, supplemented by a classical Mendelian cross between two inbred strains which are known to differ markedly in level of exploratory behaviour (van Abeelen, 1974). The diallel cross (Hayman, 
$1954 a, b)$ has been used widely to analyse the genetics of diverse traits in plant breeding (Mather and Jinks, 1982), behavioural studies (e.g., Broadhurst, 1960; Godoy-Herrera et al., 1984), and animal physiology (e.g., van der Laarse et al., 1984).

\section{MATERIALS AND METHODS}

\section{(i) Mice}

Litters used in the classical cross were the first, second, or third litter of a particular dam. For the diallel cross we used only second litters. In both crosses, to randomise possible postnatal maternal effects, almost all newborn pups were fostered to lactating mothers from a random-bred stock. Male litter mates were housed $2-5$ in plastic breeding cages with a metal cover and a bedding of wood shavings. Individuals were marked with a purple dye for identification. The cages were cleaned once a week. Food pellets (Hope Farms) and tap water were always available. At the age of 4-5 weeks, the animals were dipped in an ectoparasite-killing solution. They were maintained in an air-conditioned mouse room $\left(21^{\circ} \mathrm{C}\right)$ where an $11 \mathrm{~L}$ : $13 \mathrm{D}$ schedule prevailed. In the autumn and winter, lights were turned on at 07.00 hours, whereas in spring and summer lights were turned on at 06.00 hours (MET).

For the classical cross the following numbers of males were used: $\mathrm{C} 57 \mathrm{BL} / 6 \mathrm{~J} / / \mathrm{Nmg}, 59$; $\mathrm{DBA} / 2 \mathrm{~J} / / \mathrm{Nmg}, 54 ; \mathrm{F}_{1}$ (=DB), 53; $\mathrm{F}_{1}(=\mathrm{BD}), 41$; $\mathrm{F}_{2}(=\mathrm{DB} \times \mathrm{DB}), 70 ; \mathrm{B}_{1}(=\mathrm{DB} \times \mathrm{B}), 64 ; \mathrm{B}_{2}(=\mathrm{DB} \times$ $\mathrm{D}), 70$. The first three generations were bred and tested first. As parentals for the diallel cross we chose the inbred strains $\mathrm{C} 57 \mathrm{BL} / 6 \mathrm{~J} / / \mathrm{Nmg}$ (B), DBA/2J//Nmg (D), C3Hf/St//Nmg (H; Staats, 1980 ), and CPB-K//Nmg (K; contrary to Staats, 1976, this is not an albino strain). The diallel comprised 300 animals from 100 litters in all. From all 16 possible crosses one litter (hybrids) or two litters (inbreds) were raised simultaneously, constituting one replication or block. Five such replications were bred consecutively. Three males from each litter were observed in the open-field.

\section{(ii) Observation}

The novel environment was an illuminated openfield, measuring $109 \times 49 \times 49 \mathrm{~cm}$, with a transparent front pane. Against the back wall, $5 \mathrm{~cm}$ above the floor, a prismatic metal object, measuring $12 \times 12 \times 7 \times 7 \mathrm{~cm}$, was attached, providing the mice with an opportunity for exploratory object-leaning and object-sniffing. The floor was divided into 21 rectangles by painted lines. Before each test session, the observation cage was thoroughly wiped, but not rinsed, so that it was probably richly structured with mouse odours.

Observations took place between 09.30 and 18.00 hours (except for a few mice that were observed between 18.00 and 19.30 hours) in a sequence that varied randomly over genotypes. Single males, aged $90 \pm 7$ days, were placed in the centre of the cage and observed directly and continuously for $20 \mathrm{~min}$. If grooming or freezing, which are both relatively time-consuming, occurred for a total duration of $k \mathrm{sec}$, that session was prolonged for $k \mathrm{sec}$ as a correction for lost opportunities to carry out the rapidly-executed exploratory acts. Locomotor activity and the frequencies of rearing, leaning, object-leaning, sniffing, object-sniffing, jumping, gnawing, grooming, defecation, and urination were registered manually on counters. Durations of sessions and of grooming and freezing were recorded with stopwatches.

Behavioural components were defined as follows: Locomotor activity: the number of line crossings, disregarding the tail. Rearing: standing upright on the hind legs, while the forepaws are not touching any surface. Leaning: leaning against the wall; standing on its hind legs, the mouse places one or two forepaws against the wall. Leaning is often but not always combined with sniffing at the wall. Object-leaning: one or two forepaws are placed against the object; this posture is not always combined with sniffing at the object. Sniffing: the nose is held close to a particular spot while movements of the nasal skin take place. Doing this, the animal may be moving. Object-sniffing: the nose is held close to the object or is actually touching it, showing the characteristic sniffing movements. Jumping: all four legs simultaneously lose contact with the floor. Gnawing: occasionally animals gnawed at edges of the floor and walls. This was recorded if it was audible. Defecation: recorded by counting the boluses deposited. Urination: the presence or absence of urine was recorded after each session. Grooming: these activities included face-cleaning, fur-licking, and scratching. Freezing: the animal is, apart from breathing, completely motionless.

\section{(iii) Analysis}

The scaling procedure applied has been described by Crusio et al. (1984). Briefly, the homogeneity of the variances of nonsegregating generations 
was evaluated by means of Barlett's test. Further, Pearson product-moment correlations between means and standard deviations, means and variances, and squared means and variances were calculated in order to check for any systematic covariation between these measures. Because the nonsegregating generations had population sizes of less than 50 litters, no test for normal distributions of the data was performed; only a visual inspection was possible. A scale was judged appropriate if none of the mentioned tests, that is, Bartlett's test and the three different productmoment correlations, was significant and the data appeared to be normally distributed. Transformations used were $\ln (x+1), \sqrt{x}+\sqrt{(x+1)}, 1 /(x+1)$, and the untransformed scale. For the diallel-cross analysis we used the $\log (x+1)$ transformation instead of $\ln (x+1)$ and, in addition, the $x^{1 / 3}$ and $x^{2}$ transformations. An adequate scale could not always be found. In such cases a scale was chosen that violated the tested assumptions as little as possible.

A model comprising seven parameters is necessary to describe all variation between the generations of our classical cross (table $1 ; c f$. Mather and Jinks, 1982): the general mean $(m)$, additive genetic variation $([d])$, dominance $([h])$, epistasis ([i]-, $[j]-$, and $[l]$-type), and a reciprocal effect $\left(\left[d_{r}\right]\right)$ which is a composite of $[\mathrm{dm}]$, the additive maternal effect, and $\left[d_{x}\right]$, the additive contributions to the generation means of sexlinked genes. To analyse our data we searched for the best-fitting and most parsimonious model. For this purpose we used a method based on Cavalli's (1952) joint scaling test. In its original form, weighted least squares for $m,[d]$ and $[h]$ can be estimated from the generation means, neglecting any epistasis. For weighting, the reciprocals of the squared standard errors of the means are used. A chi-square test can be applied to the expected and observed generation means. If the probability is

Table 1 Model employed in the analysis of the classical cross between the inbred mouse strains C57BL/6 and DBA/2. See text for explanation

\begin{tabular}{lrrrrrrr}
\hline & \multicolumn{7}{c}{ Parameter } \\
\cline { 2 - 8 } Generation & $m$ & {$[d]$} & {$[h]$} & {$[i]$} & {$[j]$} & {$[l]$} & {$\left[d_{r}\right]$} \\
\hline $\mathrm{C} 57 \mathrm{BL} / 6(\mathrm{~B})$ & 1 & 1 & 0 & 1 & 0 & 0 & 1 \\
$\mathrm{DBA} / 2$ (D) & 1 & -1 & 0 & 1 & 0 & 0 & -1 \\
$\mathrm{DB}$ & 1 & 0 & 1 & 0 & 0 & 1 & -1 \\
$\mathrm{BD}$ & 1 & 0 & 1 & 0 & 0 & 1 & 1 \\
$\mathrm{DB} \times \mathrm{DB}$ & 1 & 0 & $\frac{1}{2}$ & 0 & 0 & $\frac{1}{4}$ & 0 \\
$\mathrm{DB} \times \mathrm{B}$ & 1 & $\frac{1}{2}$ & $\frac{1}{2}$ & $\frac{1}{4}$ & $\frac{1}{4}$ & $\frac{1}{4}$ & 0 \\
$\mathrm{DB} \times \mathrm{D}$ & 1 & $-\frac{1}{2}$ & $\frac{1}{2}$ & $\frac{1}{4}$ & $-\frac{1}{4}$ & $\frac{1}{4}$ & 0 \\
\hline
\end{tabular}

nonsignificant, epistasis is assumed to be absent. The procedure, with a worked example, is presented in full by Gale et al. (1977) and Mather and Jinks (1982). This test can easily be expanded to more complex models. Kerbusch et al. (1981) used this property in their model-searching procedure, in which a joint scaling test is applied to all possible models, with some restrictions.

The analysis of variance and the variancecovariance analysis of the diallel cross followed the methods of Hayman (1954a and $b$ ) described in detail by Crusio et al. (1984).

\section{RESULTS AND DISCUSSION}

The results of the behavioural observations are arranged in tables 2 (classical cross) and 3 (diallel cross). The findings from the model-searching procedure as applied to the data from table 2 are presented in table 4. The Hayman diallel-cross ANOVA can be found in table 5 and the results of the $V: W$ analysis in table 6 .

In the classical-cross analysis we failed to find adequate scales for locomotor activity, sniffing, gnawing, urination, grooming frequency, and grooming duration. In the diallel cross we could not find an adequate scale for defecation only. We chose those scales that violated our preset criteria the least. Where different scales were used in the two analyses, comparisons are still valid because, generally, the results were invariant over scale transformations. The direction of the dominance found did not vary among transformations, except for the reciprocal scale where the sign of $[h]$ was reversed. In what follows, only the more important findings are described and discussed; the details of analysis can be studied by perusing the tables.

Locomotor activity Hayman's ANOVA indicated large additive genetic effects and directional dominance for high scores. The absence of a significant correlation between $W+V$ and the parental scores leads us to conclude, however, that the genetic architecture of locomotor activity is characterised by large additive genetic effects and ambidirectional dominance. This explains the unrealistically low estimate of $k$ (the minimum number of effective genetic factors). The $m d h l$ model found in the classical cross agrees with the above genetic architecture.

Rearing A strong reciprocal effect was detected in the diallel in such a direction that hybrids tended to phenotypically resemble the maternal strain. All analyses indicated epistatic interactions. The diallel cross suggests directional 
Table 2 Results of the classical cross between strains DBA/2 and C57BL/6 and Mather's scaling tests

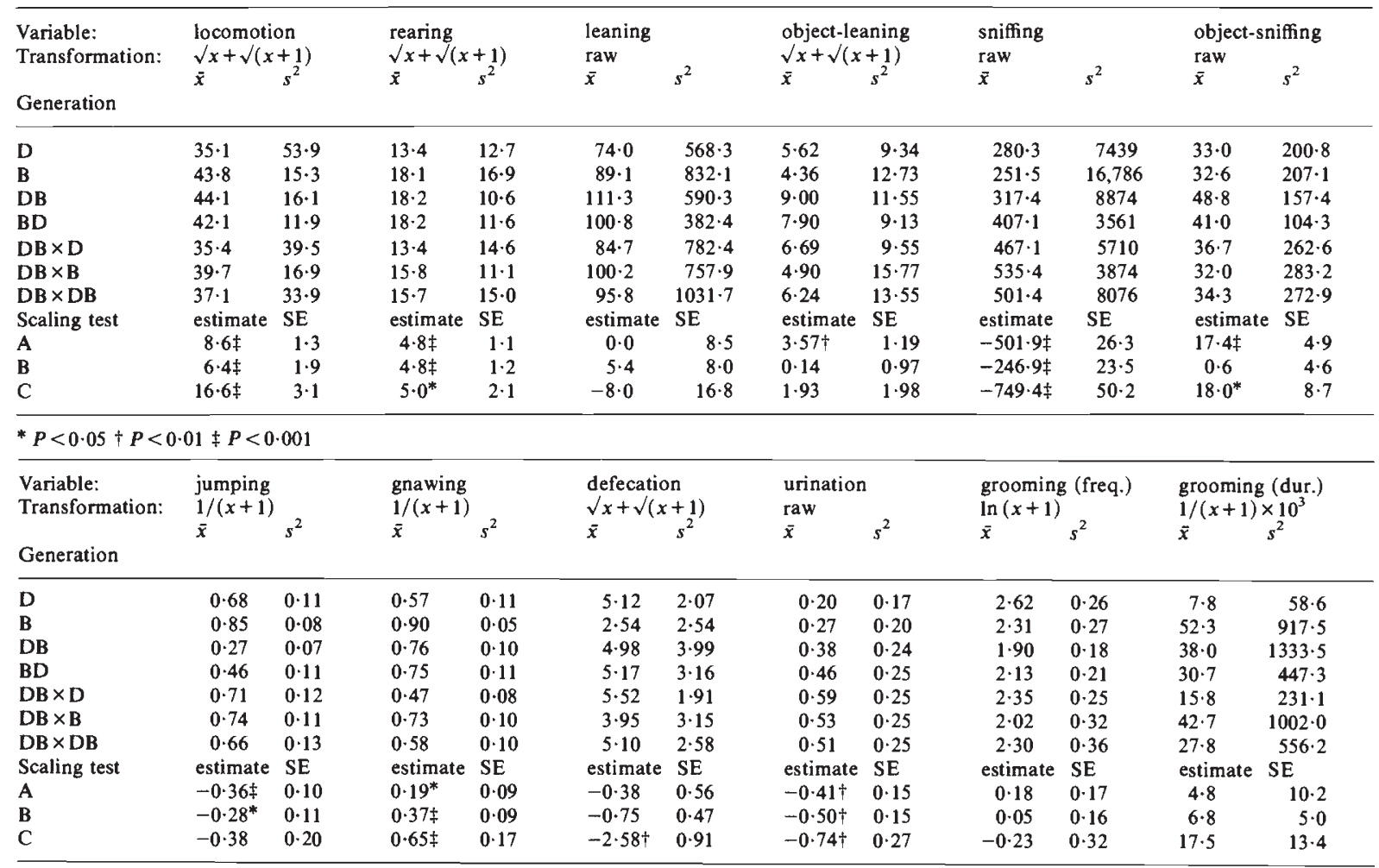

Table 3 Untransformed cell means from the diallel cross between the inbred mouse strains C57BL/6 (B), DBA/2 (D), C3H/St $(\mathrm{H})$, and $\mathrm{CPB}-\mathrm{K}(\mathrm{K})$

\begin{tabular}{|c|c|c|c|c|c|c|c|c|}
\hline $\begin{array}{l}0 \\
q\end{array}$ & B & D & $\begin{array}{c}\mathbf{H} \\
\text { locomotion }\end{array}$ & $\mathbf{K}$ & B & D & $\begin{array}{l}\mathbf{H} \\
\text { rearing }\end{array}$ & $\mathrm{K}$ \\
\hline B & $446 \cdot 3$ & $411 \cdot 9$ & $391 \cdot 3$ & $367 \cdot 0$ & $62 \cdot 0$ & $74 \cdot 1$ & 59.7 & $84 \cdot 2$ \\
\hline D & $397 \cdot 1$ & $257 \cdot 3$ & $398 \cdot 1$ & $347 \cdot 8$ & $65 \cdot 7$ & $43 \cdot 2$ & $62 \cdot 0$ & $82 \cdot 7$ \\
\hline K & $285 \cdot 0$ & $294 \cdot 6$ & $\begin{array}{l}306 \cdot 9 \\
\text { leaning }\end{array}$ & $189 \cdot 3$ & $47 \cdot 3$ & $65 \cdot 9$ & $\begin{array}{c}58 \cdot 5 \\
\text { object-leaning }\end{array}$ & $23 \cdot 0$ \\
\hline B & $83 \cdot 7$ & $97 \cdot 7$ & $117 \cdot 9$ & 90.9 & $10 \cdot 8$ & $20 \cdot 7$ & $15 \cdot 0$ & $20 \cdot 6$ \\
\hline K & $65 \cdot 1$ & $68 \cdot 9$ & $\begin{array}{c}82 \cdot 9 \\
\text { sniffing }\end{array}$ & $46 \cdot 2$ & $11 \cdot 1$ & $16 \cdot 0$ & $\begin{array}{c}21 \cdot 7 \\
\text { object-sniffing }\end{array}$ & $7 \cdot 8$ \\
\hline B & $673 \cdot 0$ & $650 \cdot 6$ & $666 \cdot 4$ & $606 \cdot 6$ & $37 \cdot 1$ & $45 \cdot 3$ & $41 \cdot 2$ & $41 \cdot 4$ \\
\hline D & $564 \cdot 2$ & 480.5 & $556 \cdot 5$ & $551 \cdot 1$ & $43 \cdot 9$ & $33 \cdot 3$ & $50 \cdot 4$ & $43 \cdot 2$ \\
\hline $\mathbf{H}$ & $629 \cdot 6$ & $573 \cdot 1$ & $590 \cdot 2$ & $588 \cdot 3$ & $47 \cdot 5$ & $52 \cdot 1$ & $55 \cdot 5$ & $52 \cdot 3$ \\
\hline K & $562 \cdot 0$ & $608 \cdot 6$ & $\begin{array}{l}597 \cdot 3 \\
\text { jumping }\end{array}$ & 523.9 & $29 \cdot 5$ & $37 \cdot 5$ & $\begin{array}{l}47 \cdot 5 \\
\text { gnawing }\end{array}$ & $26 \cdot 5$ \\
\hline $\mathrm{K}$ & $1 \cdot 3$ & $2 \cdot 9$ & $\begin{array}{c}2 \cdot 5 \\
\text { defecation }\end{array}$ & $0 \cdot 2$ & 0.4 & $0 \cdot 2$ & $\begin{array}{c}0.9 \\
\text { urination }\end{array}$ & 0.2 \\
\hline B & $3 \cdot 9$ & $6 \cdot 5$ & 5.4 & $6 \cdot 2$ & 0.4 & 0.5 & 0.5 & 0.4 \\
\hline D & $7 \cdot 3$ & $6 \cdot 8$ & $5 \cdot 9$ & $4 \cdot 7$ & 0.7 & 0.5 & $0 \cdot 2$ & 0.2 \\
\hline $\mathbf{H}$ & $5 \cdot 3$ & $5 \cdot 1$ & $4 \cdot 2$ & $9 \cdot 6$ & 0.4 & $0 \cdot 3$ & $0 \cdot \overline{3}$ & 0.9 \\
\hline K & $5 \cdot 3$ & $9 \cdot 7$ & $9 \cdot 3$ & $6 \cdot 3$ & 0.5 & 0.8 & 0.7 & $0 \cdot 2$ \\
\hline \multicolumn{6}{|c|}{ grooming frequency } & \multicolumn{3}{|c|}{ grooming duration } \\
\hline B & $6 \cdot 8$ & $9 \cdot 6$ & $7 \cdot 6$ & $9 \cdot 8$ & $25 \cdot 8$ & $56 \cdot 6$ & 32.9 & $77 \cdot 7$ \\
\hline D & $10 \cdot 0$ & $13 \cdot 4$ & $8 \cdot 8$ & $7 \cdot 7$ & $71 \cdot 3$ & $219 \cdot 2$ & $52 \cdot 3$ & $47 \cdot 3$ \\
\hline $\mathbf{H}$ & $5 \cdot 0$ & $5 \cdot 9$ & $6 \cdot 8$ & $10 \cdot 0$ & $21 \cdot 8$ & 28.9 & $40 \cdot 2$ & $43 \cdot 7$ \\
\hline K & $9 \cdot 5$ & $8 \cdot 8$ & $7 \cdot 4$ & $10 \cdot 8$ & 75.9 & $67 \cdot 1$ & $39 \cdot 4$ & $84 \cdot 2$ \\
\hline
\end{tabular}


dominance for high scores. This is not compatible with the results of the analyses of the classical cross, which clearly showed that, at least for strains $\mathrm{C} 57 \mathrm{BL} / 6$ and $\mathrm{DBA} / 2$, dominance is in the opposite direction. The diallel cross should have indicated either this or ambidirectional dominance. Van Abeelen $(1975 ; 1977)$, in his selection lines SRH and SRL, isolated one of the genetic units for which strains C57BL/6 and DBA/ 2 differ. A classical-cross analysis of these inbred selection lines showed additive genetic variation only (van Abeelen, 1975; Kerbusch and van Abeelen, 1981). However, the latter authors used the reciprocals of the variances as weights in the Cavalli procedure, instead of the reciprocals of the squared standard errors of the means. If we apply the model-searching procedure to their data, using the correct weights, an $m d h$ model is obtained (transformation $\ln (x+1) ; m=3 \cdot 131,[d]=0 \cdot 566,[h]=$ $\left.0 \cdot 304, \chi^{2}=1 \cdot 699, \mathrm{df}=3 ; P>0 \cdot 70\right)$. Therefore, $[h]$ is positive for the isolated genetic unit. Yet we find a negative estimate of $[h]$ when more genes are sampled in the cross between $\mathrm{C} 57 \mathrm{BL} / 6$ and $\mathrm{DBA} / 2$. This is only compatible with an ambidirectional nature of the dominance.

Leaning Both analyses agree in that epistasis does not form part of the genetic architecture of wall-leaning and that dominance is clearly present and that it is ambidirectional. The significant difference between $\mathrm{BD}$ and $\mathrm{DB}$ in the classical cross did not materialise in the diallel cross. This strengthtens the results of the model-searching procedure, which produced a model not including a reciprocal effect. The differences between the findings for wall-leaning and those for rearing can be explained by the differential perception of tactile stimuli through the vibrissae.

Object-leaning The large complementary epistasis found in the classical cross was not detected in the diallel cross. The latter indicated ambidirectional dominance; consequently, the estimate obtained for $k$ is too small. The deviation of the joint slope approached significance $(t=$ $1.95 ; 0.05<P<0.10)$. This indicates that the assumptions were not completely satisfied. The genetic underpinnings of this phenotype apparently contain additive genetic variation and ambidirectional dominance, with only minor epistatic effects present in some crosses.

Sniffing The classical cross between C57BL/6 and DBA $/ 2$ showed large duplicate epistasis not found in the diallel cross. The genetic architecture of sniffing contains additive genetic variation and ambidirectional dominance with, overall, only minor duplicate epistasis.
Object-sniffing Here too, the classical cross indicated duplicate epistasis. Dominance was found in the joint regression analysis. The positive, corrected intercept points to incomplete dominance. This dominance seems to be directional for high scores because $W+V$ is negatively correlated with the parental values but, since the classical cross revealed directional dominance for low scores, dominance must be ambidirectional.

Jumping The diallel cross points to directional dominance for high scores but the large epistatic effects render this finding doubtful and do not allow firm conclusions to be drawn on the nature of the genetic architecture.

Gnawing Dominance and duplicate epistasis emerged from the classical cross. The diallel cross detected directional dominance for low scores, whereas the classical cross revealed directional dominance for high untransformed scores. Hence, dominance must be ambidirectional Epistasis appeared in the cross between $\mathrm{C} 57 \mathrm{BL} / 6$ and DBA/ 2 but, according to the diallel cross analysis, it turns out to be of minor importance.

Defecation The classical-cross analysis revealed no significant dominance, contrary to the diallel cross where ambidirectional dominance was found. However, the [i]-type epistasis occurring in strains $\mathrm{C} 57 \mathrm{BL} / 6$ and $\mathrm{DBA} / 2$ might mimic dominance effects and, moreover, epistasis is large enough to be detected in the diallel cross. Thus, no further conclusions can be drawn on the genetic architecture.

Urination Only residual dominance effects came up in Hayman's ANOVA. This is not in accordance with the results of the $V: W$ analysis, because the correlation between the parental values and $W+V$ is highly significant. This would indicate dominance in the direction of low transformed scores (that means: high untransformed scores). However, the dominance order is B-D-H$\mathrm{K}$, which is not the same as the phenotypical rank order of the strains. Significant strain differences being absent, dominance seems ambidirectional. Dominance and duplicate epistasis were the only effects seen in the classical cross. A genetic architecture of ambidirectional dominance and a relatively low degree of duplicate epistasis seems acceptable.

Grooming frequency The Hayman analysis shows additive genetic effects and dominance, but the nature of the dominance is not revealed. The values of $W+V$ did not correlate with the parental values. The genetic architecture comprises additive genetic variation and ambidirectional dominance. 
Table 4 Models obtained by applying the model-searching procedure to the data from table 2

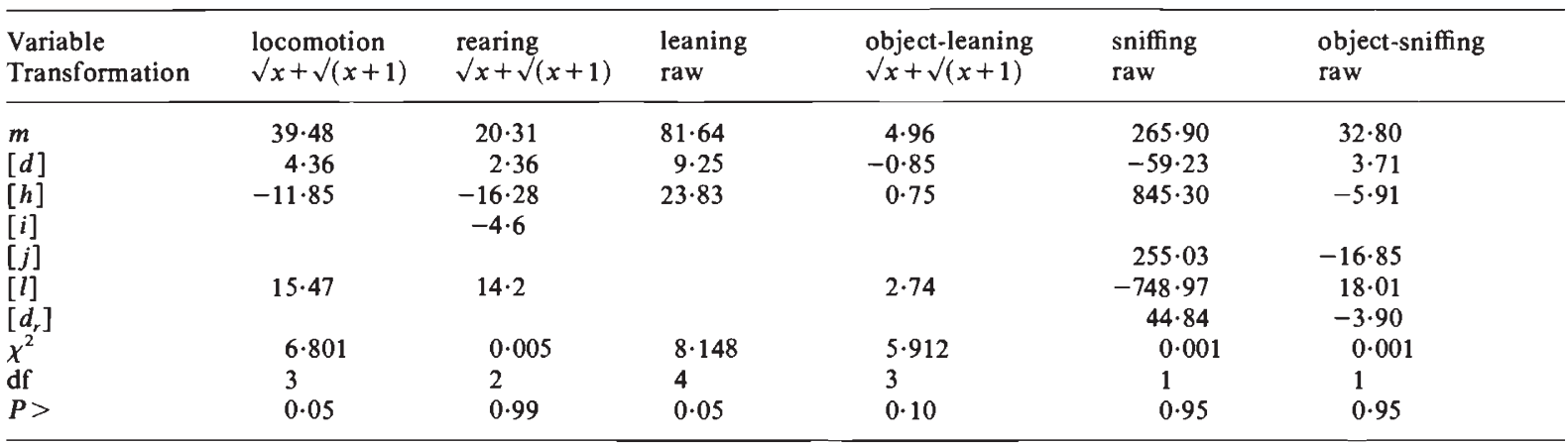

Table $5 F$-values obtained in the Hayman diallel cross analysis of the results from table 3

\begin{tabular}{|c|c|c|c|c|c|c|c|}
\hline $\begin{array}{l}\text { Variable } \\
\text { Transformation }\end{array}$ & $\mathrm{df}$ & $\begin{array}{l}\text { locomotion } \\
\text { raw }\end{array}$ & $\begin{array}{l}\text { rearing } \\
\sqrt{ } x+\sqrt{ }(x+1)\end{array}$ & $\begin{array}{l}\text { leaning } \\
\sqrt{ } x+\sqrt{(x+1)}\end{array}$ & $\begin{array}{l}\text { object-leaning } \\
\text { raw }\end{array}$ & $\begin{array}{l}\text { sniffing } \\
\text { raw }\end{array}$ & $\begin{array}{l}\text { object-sniffing } \\
\text { raw }\end{array}$ \\
\hline Between cells & 15,80 & $18 \cdot 39 \ddagger$ & $6 \cdot 95 \ddagger$ & $9 \cdot 02 \ddagger$ & $3 \cdot 65 \ddagger$ & $6 \cdot 29 \ddagger$ & $4 \cdot 50 \ddagger$ \\
\hline$b$ & 6,24 & $15 \cdot 01 \ddagger$ & $10 \cdot 39 \ddagger$ & $6.07 \ddagger$ & $6 \cdot 89 \ddagger$ & $5.45 \dagger$ & $5.02 \dagger$ \\
\hline$b_{1}$ & 1,4 & $19 \cdot 61^{*}$ & $17 \cdot 08^{*}$ & $15 \cdot 04^{*}$ & $42 \cdot 88^{\dagger}$ & $7 \cdot 79 *$ & $166 \cdot 85 \ddagger$ \\
\hline$b_{2}$ & 3,12 & $21 \cdot 61 \ddagger$ & $10 \cdot 56 \dagger$ & $1 \cdot 18$ & $2 \cdot 41$ & $3 \cdot 35$ & $2 \cdot 87$ \\
\hline$d$ & 3,12 & $0 \cdot 30$ & $0 \cdot 12$ & 0.53 & 1.00 & $0 \cdot 10$ & 0.36 \\
\hline Blocks & 4,80 & $6.88 \dagger$ & $1 \cdot 64$ & $4 \cdot 05^{*}$ & $10.75 \ddagger$ & $11 \cdot 67 \ddagger$ & $6 \cdot 83 \ddagger$ \\
\hline
\end{tabular}

Table 6 Results of the analysis of the variance and covariance of the data from table 3

\begin{tabular}{|c|c|c|c|c|c|c|c|c|c|c|}
\hline \multirow[t]{2}{*}{$\begin{array}{l}\text { Variable } \\
\text { Transformation }\end{array}$} & \multicolumn{2}{|c|}{$\begin{array}{l}\text { locomotion } \\
\text { raw }\end{array}$} & \multicolumn{2}{|c|}{$\begin{array}{l}\text { rearing } \\
\sqrt{x}+\sqrt{(x+1)}\end{array}$} & \multicolumn{2}{|c|}{$\begin{array}{l}\text { leaning } \\
\sqrt{x}+\sqrt{(x+1)}\end{array}$} & \multicolumn{2}{|c|}{$\begin{array}{l}\text { object-leaning } \\
\text { raw }\end{array}$} & \multicolumn{2}{|c|}{$\begin{array}{l}\text { sniffing } \\
\text { raw }\end{array}$} \\
\hline & $\mathrm{df}$ & $F$ & $\mathrm{df}$ & $F$ & df & $F$ & $\mathrm{df}$ & $F$ & $\mathrm{df}$ & $F$ \\
\hline joint regression & 1,18 & $79 \cdot 45 \ddagger$ & 1,18 & $34 \cdot 50 \ddagger$ & 1,18 & $132 \cdot 53 \ddagger$ & 1,18 & $8 \cdot 37 \dagger$ & 1,18 & $20 \cdot 02 \ddagger$ \\
\hline heterogeneity & 4,14 & $2 \cdot 25$ & 4,14 & $1 \cdot 80$ & 4,14 & 0.07 & 4,14 & $1 \cdot 07$ & 4,14 & 1.93 \\
\hline \multicolumn{11}{|l|}{ Estimate } \\
\hline slope \pm SE & \multicolumn{2}{|c|}{$0.87 \pm 0.09$} & \multicolumn{2}{|c|}{$0.63 \pm 0.10 \dagger$} & \multicolumn{2}{|c|}{$0.87 \pm 0.08$} & \multicolumn{2}{|c|}{$0 \cdot 60 \pm 0 \cdot 21$} & \multicolumn{2}{|c|}{$0.81 \pm 0 \cdot 17$} \\
\hline$\frac{1}{4}\left(D-H_{1}\right) \pm S E$ & \multicolumn{2}{|c|}{$1804 \cdot 80 \pm 654 \cdot 29$} & \multicolumn{2}{|c|}{$-3 \cdot 36 \pm 2 \cdot 77$} & \multicolumn{2}{|c|}{$0.57 \pm 0.72$} & \multicolumn{2}{|c|}{$-2 \cdot 71 \pm 2 \cdot 59$} & \multicolumn{2}{|c|}{$1171 \cdot 22 \pm 807 \cdot 64$} \\
\hline$\sqrt{ }\left(H_{1} / D\right)$ & \multicolumn{2}{|c|}{0.66} & \multicolumn{2}{|c|}{$1 \cdot 75$} & \multicolumn{2}{|c|}{0.79} & \multicolumn{2}{|c|}{$1 \cdot 15$} & \multicolumn{2}{|c|}{0.55} \\
\hline$h_{(n)}^{2}$ & \multicolumn{2}{|c|}{0.49} & \multicolumn{2}{|l|}{0.03} & \multicolumn{2}{|c|}{0.46} & \multicolumn{2}{|c|}{$0 \cdot 12$} & \multicolumn{2}{|c|}{$0 \cdot 24$} \\
\hline$h_{(b)}^{2(n)}$ & \multicolumn{2}{|c|}{0.64} & \multicolumn{2}{|c|}{0.40} & \multicolumn{2}{|c|}{0.58} & \multicolumn{2}{|c|}{$0 \cdot 22$} & \multicolumn{2}{|c|}{$0 \cdot 31$} \\
\hline$r_{W+V, P}$ & \multicolumn{2}{|c|}{$\begin{array}{r}-0.31 \\
1.02\end{array}$} & \multicolumn{2}{|c|}{$-0.70 \ddagger$} & \multicolumn{2}{|c|}{$-0 \cdot 36$} & \multicolumn{2}{|c|}{-0.06} & \multicolumn{2}{|c|}{-0.03} \\
\hline$k$ & \multicolumn{2}{|c|}{1.02} & - & & $2 \cdot 03$ & & $1 \cdot 99$ & & & \\
\hline
\end{tabular}

* $P<0.05$

$+P<0.01$

$\ddagger P<0 \cdot 001$

- Not calculated

Grooming duration The diallel analysis indicated additive genetic variation and ambidirectional dominance.

Freezing This behaviour occurred rarely and a biometrical analysis seemed inappropriate.

\section{DISCUSSION}

Low estimates were generally obtained for the minimum number of effective factors $(k)$. Unifactorial regulation of activity and exploration in a 


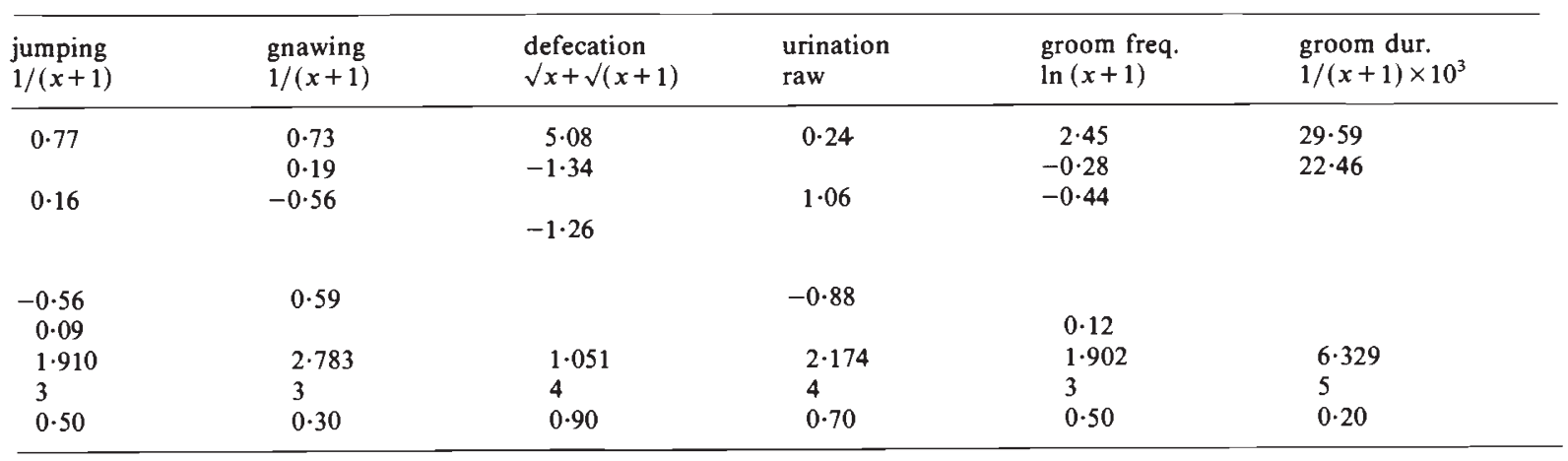

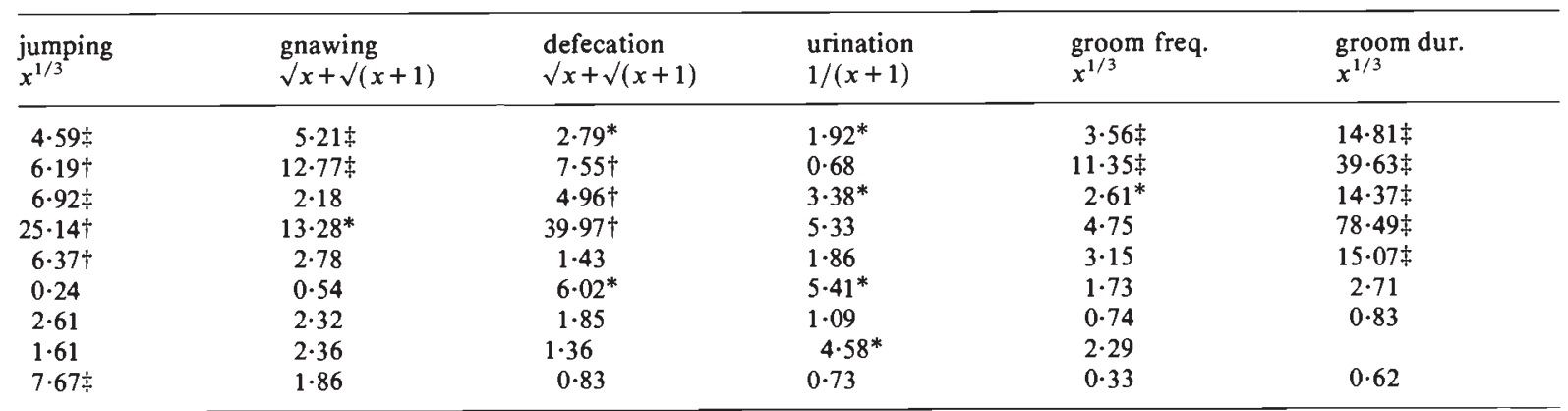

\begin{tabular}{|c|c|c|c|c|c|c|c|c|c|c|c|c|c|}
\hline \multicolumn{2}{|c|}{$\begin{array}{l}\text { object-sniffing } \\
\text { raw }\end{array}$} & \multicolumn{2}{|c|}{$\underset{x^{1 / 3}}{\text { jumping }}$} & \multicolumn{2}{|c|}{$\begin{array}{l}\text { gnawing } \\
\sqrt{ } x+\sqrt{ }(x+1)\end{array}$} & \multicolumn{2}{|c|}{$\begin{array}{l}\text { defecation } \\
\sqrt{ } x+\sqrt{ }(x+1)\end{array}$} & \multicolumn{2}{|c|}{$\begin{array}{l}\text { urination } \\
1 /(x+1)\end{array}$} & \multicolumn{2}{|c|}{$\begin{array}{l}\text { groom freq. } \\
x^{1 / 3}\end{array}$} & \multicolumn{2}{|c|}{$\underset{x^{1 / 3}}{\text { groom dur. }}$} \\
\hline $\mathrm{df}$ & $F$ & $\mathrm{df}$ & $F$ & df & $F$ & $\mathrm{df}$ & $F$ & df & $F$ & df & $F$ & df & $F$ \\
\hline 1,18 & $31 \cdot 72 \ddagger$ & 1,18 & $8 \cdot 21^{*}$ & 1,18 & $55 \cdot 37 \ddagger$ & 1,18 & $8 \cdot 10^{*}$ & 1,18 & $11 \cdot 87 \dagger$ & 1,18 & $9 \cdot 21 \dagger$ & 1,18 & $78 \cdot 13 \ddagger$ \\
\hline 4,14 & 0.57 & 4,14 & $1 \cdot 44$ & 4,14 & $1 \cdot 12$ & 4,14 & 0.64 & 4,14 & $1 \cdot 58$ & 4,14 & 0.40 & 4,14 & 0.90 \\
\hline \multicolumn{2}{|c|}{$0.89 \pm 0.17$} & \multicolumn{2}{|c|}{$0.47 \pm 0.16^{\dagger}$} & \multicolumn{2}{|c|}{$1 \cdot 06 \pm 0.14$} & \multicolumn{2}{|c|}{$0.54 \pm 0 \cdot 20^{*}$} & \multicolumn{2}{|c|}{$0.73 \pm 0.20$} & \multicolumn{2}{|c|}{$0.66 \pm 0.23$} & \multicolumn{2}{|c|}{$1 \cdot 00 \pm 0 \cdot 11$} \\
\hline \multicolumn{2}{|c|}{$22 \cdot 70 \pm 2 \cdot 85 \ddagger$} & \multicolumn{2}{|c|}{$-0.06 \pm 0.08$} & \multicolumn{2}{|c|}{$0 \cdot 12 \pm 0.08$} & \multicolumn{2}{|c|}{$-0 \cdot 15 \pm 0 \cdot 33$} & \multicolumn{2}{|c|}{$-0.01 \pm 0.01$} & \multicolumn{2}{|c|}{$0.01 \pm 0.01$} & \multicolumn{2}{|c|}{$0.05 \pm 0.24$} \\
\hline \multicolumn{2}{|c|}{0.60} & \multicolumn{2}{|c|}{$1 \cdot 52$} & \multicolumn{2}{|c|}{0.59} & \multicolumn{2}{|c|}{$1 \cdot 65$} & \multicolumn{2}{|c|}{$4 \cdot 80$} & \multicolumn{2}{|c|}{0.76} & \multicolumn{2}{|c|}{0.95} \\
\hline \multicolumn{2}{|l|}{$0 \cdot 24$} & \multicolumn{2}{|c|}{0.07} & \multicolumn{2}{|l|}{$0 \cdot 31$} & \multicolumn{2}{|l|}{0.07} & \multicolumn{2}{|c|}{0.00} & \multicolumn{2}{|l|}{$0 \cdot 16$} & \multicolumn{2}{|l|}{0.35} \\
\hline \multicolumn{2}{|l|}{$0 \cdot 30$} & \multicolumn{2}{|c|}{$0 \cdot 26$} & $0 \cdot 38$ & & $0 \cdot 22$ & & $0 \cdot 12$ & & 0.25 & & $0 \cdot 64$ & \\
\hline $0.60 \dagger$ & & -0.69 & & $0.51^{*}$ & & -0.26 & & 0.68 & & $0 \cdot 37$ & & $0 \cdot 33$ & \\
\hline $1 \cdot 55$ & & - & & 0.99 & & - & & 0.27 & & 0.08 & & 0.47 & \\
\hline
\end{tabular}

novel environment seems improbable, however, for several reasons. First, the ambidirectional dominance (already implying multiple factors) renders the estimates of $k$ unreliable. Second, the fairly gradual response to artificial selection (van Abeelen, 1974) points to a polygenic system. Simmel and Bagwell (1983) claimed that exploration, contrary to general activity, is under monogenic control. They based their assertion on the findings of Oliverio et al. (1973) and van
Abeelen $(1975 ; 1977)$. The conclusions of Oliverio et al. (1973) were heavily criticised by Lush (1981). Van Abeelen's experiments made unifactorial control of the differences in activity and exploratory rearing between the inbred selection lines SRH and SRL very likely. The selection procedure establishing these strains, however, was specifically designed to isolate as few genetic factors as possible, a point misunderstood by Simmel and Bagwell (1983). 
A genetic architecture of additive genetic effects and ambidirectional dominance was found for almost all variables where epistatic effects are of minor importance: locomotor activity, leaning, object-leaning, sniffing, object-sniffing, gnawing, urination, and grooming. For these phenotypes past stabilising selection is inferred. For the other ones, no conclusions on the nature of dominance can be drawn because large epistatic interactions were found. Rearing is an exception since some of the findings indicated ambidirectional dominance. In summary, no inferences can be made about the evolutionary history of jumping and defecation.

The duplicate epistasis found in the classical cross for almost all variables might be due to seasonal effects: the $F_{2}$ and backcross generations were observed at later dates than the other generations. The absence of block effects in our diallel cross for several variables which showed duplicate epistasis in the classical cross, however, renders this possibility less likely. The duplicate epistasis is most probably real. In this connection we may mention the supposed inability of Mather's A, $\mathrm{B}$, and $\mathrm{C}$ tests to detect epistatic interactions, as reported by Kerbusch et al. (1981). In the present study, however, these tests proved to be always in accordance with the analysis of the means. This discrepancy must be caused by Kerbusch et al. (1981) using incorrect weights, not only in Cavalli's joint-scaling test, but also in Mather's ABC-tests.

An evolutionary history of stablising selection is inferred for some phenotypes that cannot be classified as exploratory: locomotor activity, grooming frequency, and grooming duration. Locomotion need not be directly related to exploration (Simmel and Bagwell, 1983). In exploring novel surroundings, oriented locomotor activity is necessary but random activity could detract from exploration and then be unfavourable. The results were exactly as we would expect, namely an evolutionary past of stabilising selection for locomotion. The situation for grooming is different. When entering a novel environment, low levels are advantageous for the animal. In fact, the bulk of its grooming activities is executed near the end of the observation session, i.e. after the novel environment has, at least in part, been explored. This agrees with the stabilising selection inferred for grooming.

The present biometrical-genetic investigation shows that an evolutionary past of stabilising selection can be inferred for mouse exploratory behaviour in a novel environment. As put forward in the introduction, the adaptive significance of intermediate levels of exploration probably rests on efficient gathering of useful information about the environment, on the one hand, and avoidance of predation, on the other.

Acknowledgements We thank Dr J. M. L. Kerbusch (University of Nijmegen) for advice and for the computer programme of his modelsearching procedure, Anne K. Kremer (State University of Utrecht) for kindly providing breeders of strain CPB-K, Anton Buis and Ron Engels for their skilful biotechnical assistance, and Professor A. P. van Overbeeke for reading a first version of the manuscript.

\section{REFERENCES}

BARnetT, S. A. 1958. Exploratory behaviour. Br. J. Psychol., 49, 289-310.

BARNETT, S. A. AND COWAN, P. E. 1976. Activity, exploration, curiosity and fear: An ethological study. Interdisc. Sci. Rev., $1,43-62$.

BROADHURST, P. L. 1960. Applications of biometrical genetics to the inheritance of behaviour. In H. J. Eysenck (ed.), Experiments in Personality. Vol. I. Psychogenetics and Psychopharmacology. London, Routledge and Kegan Paul.

BROADHURST, P. L. AND JINKS, J. L. 1974. What genetical architecture can tell us about the natural selection of behavioural traits. In J. H. F. van Abeelen (ed.), The Genetics of Behaviour, Amsterdam, North-Holland and New York, American Elsevier.

CAVALLI, L. L. 1952. An analysis of linkage in quantitative inheritance. In E. C. R. Reeve and C. H. Waddington (eds.), Quantitative Inheritance, London, HMSO.

CRUSIO, W. E., KERBUSCH, J. M. L. AND VAN ABEELEN, J. H. F. 1984. The replicated diallel cross: A generalized method of analysis. Behav. Genet., 14, 81-104.

FISHER, R. A. 1958. The Genetical Theory of Natural Selection, New York, Dover Publications.

GALE, J. G., MATHER, K. AND JINKS, J. L. 1977. Joint scaling tests. Heredity, 38, 47-51.

GODOY-HERRERA, R., BURNET, B., CONNOLLY, K. AND GOGARTY, J. 1984. The development of locomotor activity in Drosophila melanogaster larvae. Heredity, 52, 63-75.

HAYMAN, B. I. 1954a. The analysis of variance of diallel tables. Biometrics, 10, 235-244.

HAYMAN, B. I. $1954 b$. The theory and analysis of diallel crosses. Genetics, 39, 789-809.

KERBUSCH, J. M. L. AND VAN ABEELEN, J. H. F. 1981. Behavioral responses to novelty in mice: A reanalysis. Behav. Genet., 11, 373-377.

KERBUSCH, J. M. L., VAN DER STAAY, F. J. AND HENDRIKS, N. 1981. A searching procedure for transformations and models in a classical mendelian cross breeding study. Behav. Genet., 11, 239-254.

LUSH, I. E. 1981. Mouse pharmacogenetics. In R. J. Berry (ed.) Biology of the House Mouse, London, Academic Press.

MATHER, K. 1973. Genetical Structure of Populations, London, Chapman and Hall.

MATHER, K. AND JINKS, J. L. 1982. Biometrical Genetics, 3rd ed., London, Chapman and Hall. 
O'KeEFE, J. AND NADEL, L. 1978. The Hippocampus as a Cognitive Map, Oxford, Clarendon Press.

OLIVERIO, A., ELEFTHERIOU, B. E. AND BAILEY, D. W. 1973. Exploratory activity: Genetic analysis of its modification by scopolamine and amphetamine. Physiol. Behav., 10, 893-899.

ROBERTS, R. C. 1967. Some evolutionary implications of behavior. Can. J. Genet. Cytol., 9, 419-435.

SIMMEL, E. C. AND BAGWELL, M. 1983. Genetics of exploratory behavior and activity. In J. L. Fuller and E. C. Simmel (eds.), Behavior Genetics: Principles and Applications, London, Lawrence Erlbaum Assoc. Ltd.

STAATS, J. 1976. Standardized nomenclature for inbred strains of mice: Sixth listing. Cancer Res., 36, 4333-4377.

STAATS, J. 1980. Standardized nomenclature for inbred strains of mice: Seventh listing. Cancer Res., 40, 2083-2128.
VAN ABEELEN, J. H. F. 1963. Mouse mutants studied by means of ethological methods. I. Ethogram. Genetica, 34, 79-94.

VAN ABEELEN, 1974. Genotype and the cholinergic control of exploratory behaviour in mice. In J. H. F. van Abeelen (ed.), The Genetics of Behaviour, Amsterdam, NorthHolland and New York, American Elsevier.

VAN ABEELEN, J. H. F. 1975. Genetic analysis of behavioural responses to novelty in mice. Nature, 254, 239-241.

VAN ABEELEN, J. H. F. 1977. Rearing responses and locomotor activity in mice: Single-locus control. Behav. Biol., 19, 401-404.

VAN DER LAARSE, W. J., CRUSIO, W. E., MASLAM, S. AND VAN ABEELEN, J. H. F. 1984. Genetic architecture of numbers of fast and slow muscle fibres in the mouse soleus muscle. Heredity, 53, 643-647. 